\title{
Radionuclide Imaging of Viable Myocardium: Is it Underutilized?
}

\author{
Ilias Mylonas • Rob S. B. Beanlands
}

Published online: 19 February 2011

(C) The Author(s) 2011. This article is published with open access at Springerlink.com

\begin{abstract}
Coronary artery disease is the major cause of heart failure in North America. Viability assessment is important as it aims to identify patients who stand to benefit from coronary revascularization. Radionuclide modalities currently used in the assessment of viability include ${ }^{201} \mathrm{Tl} \mathrm{SPECT},{ }^{99 \mathrm{~m}} \mathrm{Tc}$-based SPECT imaging, and ${ }^{18} \mathrm{~F}$-fluorodexoyglucose $\left({ }^{18} \mathrm{~F}-\mathrm{FDG}\right)$ PET imaging. Different advances have been made in the last year to improve the sensitivity and specificity of these modalities. In addition, the optimum amount of viable (yet dysfunctional) myocardium is important to identify in patients, as a risk-benefit ratio must be considered. Patients with predominantly viable/hibernating myocardium can benefit from revascularization from a mortality and morbidity standpoint. However, in patients with minimal viability (predominantly scarred myocardium), revascularization risk may certainly be too high to justify revascularization without expected benefit. Understanding different radionuclide modalities and new developments in the assessment of viability in ischemic heart failure patients is the focus of this discussion.
\end{abstract}

Keywords Viability. Heart failure $\cdot$ SPECT $\cdot$ PET

I. Mylonas $\cdot$ R. S. B. Beanlands

National Cardiac PET Centre, Molecular Function

and Imaging Program, Division of Cardiology,

University of Ottawa Heart Institute,

Ottawa, Ontario, Canada

R. S. B. Beanlands $(\square)$

Saul and Edna Goldfarb Chair in Cardiac Imaging National

Cardiac PET Centre, University of Ottawa Heart Institute,

40 Ruskin Street,

Ottawa, Ontario K1Y 4W7, Canada

e-mail: rbeanlands@ottawaheart.ca

\section{Introduction}

Coronary artery disease (CAD) is a major cause of heart failure due to depressed left ventricular (LV) function. As such, myocardial viability is an important question one must answer in predicting outcomes and assessing treatment options. Although results of recent randomized trials such as STICH [1] are still pending, best evidence supports improved clinical outcomes after revascularization in patients with impaired LV function and evidence of myocardial viability $[2 \bullet, 3-5]$. On the other hand, patients without evidence of viable myocardium may not gain the same benefit with revascularization. Thus the clinician must carefully select the patients that will benefit from coronary revascularization as patients with impaired LV function have increased procedurally related morbidity and mortality $[1,6]$.

There are currently many methods used to estimate myocardial viability, of which radionuclide methods are the most sensitive. Among these, SPECT methods are widely available and include thallium-201 single photon emission tomography $\left({ }^{201} \mathrm{Tl}\right.$ SPECT $)$ and the use of technetium-99 $\left({ }^{99 \mathrm{~m}} \mathrm{Tc}\right)$-based SPECT imaging. Fluorine-18-fluorodeoxyglucose $\left({ }^{18} \mathrm{~F}-\mathrm{FDG}\right)$ positron emission tomography (PET) imaging has also been used where PET is available. The aim of this discussion will be to review the radionuclide imaging modalities used in the assessment of viability and highlight new findings and developments in this field.

\section{Definitions}

Viability It is important to describe the term "viability" in the capacity and spectrum of heart failure and coronary artery disease. Viability can broadly be described as "living myocardium." However, in imaging when we are discussing 
viable myocardium, we are most interested in whether dysfunctional myocardium is alive (and potentially recoverable) or dead (necrotic or scar and not recoverable). Dysfunctional but viable myocardium usually refers to regions that may be either "stunned" or "hibernating."

Stunning refers to a state of LV dysfunction that persists following an episode of ischemia after restoration of normal coronary blood flow. This may last minutes to hours following an episode of transient ischemia as may occur during exercise, or days to weeks following reperfusion of a transiently occluded coronary artery [7, 8]. The time of recovery depends on the duration, severity, and size of the ischemic insult.

Hibernation refers to metabolic downregulation of myocardium in response to a reduced state of myocardial perfusion [9]. Physiologically there is a decreased coronary flow reserve, with severe cases exhibiting a reduction of resting flow $[10,11]$. There is evidence to suggest that hibernation is the result of repetitive stunning; that is repeated ischemic insults that occur while the myocardium is still stunned. Thus, it is part of the continuum from ischemia to cell death [12]. In patients with heart failure and chronic LV dysfunction, improvements in ejection fraction (EF), end-diastolic and end-systolic volumes, and restoration of LV geometry are possible through coronary revascularization [13]. Most importantly, however, revascularization of hibernating myocardium may result in improved prognosis $[2 \bullet \bullet, 3]$. It is for these reasons that viable myocardium must be closely investigated through viability testing.

\section{SPECT Imaging}

\section{Thallium $^{201}$ SPECT}

${ }^{201} \mathrm{Tl}$ SPECT imaging is the oldest and most common method of assessing myocardial ischemia. It is also well established as a means of measuring myocardial viability. Traditional viability assessment using ${ }^{201} \mathrm{Tl}$ may be accomplished by various protocols which universally utilize the favorable kinetics of thallium-201. The initial myocardial uptake early after intravenous injection of thallium is proportional to regional blood flow. However, redistribution of ${ }^{201} \mathrm{Tl}$ is related to the rate of ${ }^{201} \mathrm{Tl}$ "washout" from the myocardium, dependant on the concentration gradient between myocytes and the thallium concentrations in the blood and the integrity of the membrane-based $\mathrm{Na}+/ \mathrm{K}+$ ATPase pump [7, 14-17]. As a potassium analogue ${ }^{201} \mathrm{Tl}$ uptake, retention, and washout are partly dependent on this pump and therefore the integrity of the cell membrane. Loss of membrane integrity is indicative of cell death. Therefore, in regions of reduced initial uptake (indicating reduced flow), ${ }^{201} \mathrm{Tl}$ washout is slower in regions that are viable because the myocardium is able retain the tracer and take up circulating ${ }^{201} \mathrm{Tl}$ via the intact membrane transport. The corollary is that when there is necrosis or scar, there is no mechanism to retain or take up ${ }^{201} \mathrm{Tl}$ and hence washout is more rapid. On imaging, the former is seen as redistribution indicating viability; while in the latter, a persistent fixed defect indicates a region with loss of viability.

The most common clinical protocols used include stressredistribution, rest-redistribution with baseline imaging of rest perfusion and delayed 3 to $4 \mathrm{~h}$ redistribution imaging, and stress-redistribution-reinjection. With standard stressredistribution or rest-redistribution imaging, the 3 to $4 \mathrm{~h}$ delayed images may underestimate viability. Subsequent data support improved accuracy for delayed 24-hour redistribution images $[18,19]$. Often though, counts are low and image quality is compromised with a single injection. This can be overcome by using a second injection of ${ }^{201} \mathrm{Tl}$ immediately after acquisition of delayed images (Fig. 1). This protocol incorporates initial image acquisition with pharmacological or exercise stress, delayed 3-4 h redistribution images, and a reinjection phase with imaging typically $1 \mathrm{~h}$ after redistribution [20]. This approach has yielded a high level of accuracy $[21,22]$ and also concordance with ${ }^{18} \mathrm{~F}-\mathrm{FDG}$ PET imaging [21, 22].

Recent efforts have been focused on improving the ability of ${ }^{201} \mathrm{Tl}$ SPECT imaging to detect viable myocardium. Adjuvant glucose administration has been proposed. A number of studies using either glucose or glucose-insulinpotassium (GIK) infusion have been published showing that ${ }^{201} \mathrm{Tl}$ uptake is enhanced, thus improving detection of viable segments [23-25]. Since ${ }^{201} \mathrm{Tl}$ and potassium possess similar kinetics, glucose administration will increase endogenous insulin release, thus ultimately acting to increase uptake of ${ }^{201} \mathrm{Tl}$ in myocardial cells. Hasbek et al. [25] recently demonstrated the benefit of oral glucose administration with ${ }^{201} \mathrm{Tl}$. Using nondiabetic patients, they performed restredistribution-24 h late SPECT. When a perfusion defect was observed, $1 \mathrm{mCi}$ of ${ }^{201} \mathrm{Tl}$ was given $30 \mathrm{~min}$ after a $75-\mathrm{g}$ oral glucose load upon completion of the 24-hour late SPECT. Repeat imaging was then performed. Glucose plus ${ }^{201} \mathrm{Tl}$ images yielded the lowest number of perfusion defects, and showed the highest segmental perfusion improvement. The authors also found that ECG-gated in the EF calculations after oral glucose administration were significantly higher compared to EF calculations prior to glucose, attributed to both enhanced ${ }^{201} \mathrm{Tl}$ uptake and improvement in wall detection in segments with perfusion defects [25]. In summary, ${ }^{201} \mathrm{Tl}$ uptake can be enhanced by oral glucose administration and the detection of viable myocardium may be improved through a simple oral glucose administration protocol that is applicable to routine daily clinical practice. 


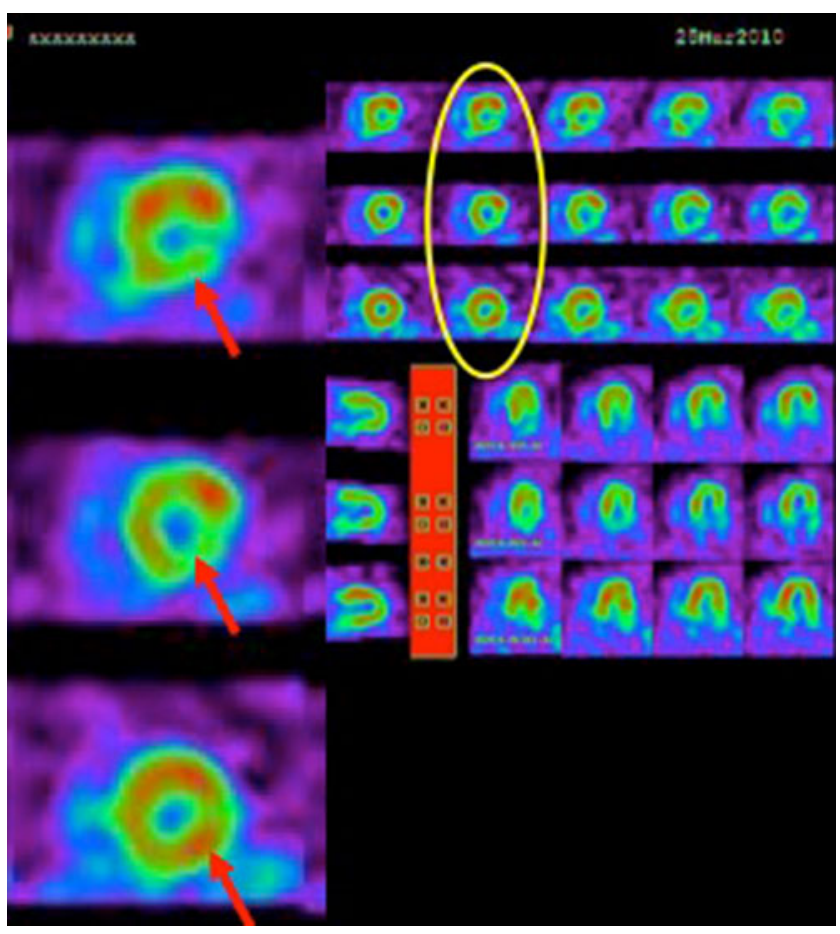

Fig. 1 Stress-rest reinjection using ${ }^{201} \mathrm{Tl}$ SPECT imaging. A 71-year-old man with late presentation ST elevation myocardial infarction. Top row/ arrow, Post-stress images demonstrate a moderate reduction in uptake in the inferolateral walls without improvement on redistribution (middle row), consistent with nontransmural scar. Third row/arrow, Reinjection of ${ }^{201} \mathrm{Tl}$ and subsequent imaging demonstrates a marked improvement in the inferolateral wall signifying viable myocardium. The patient subsequently underwent percutaneous coronary intervention of the left circumflex artery. (Images complements of James A. Stone, MD, $\mathrm{PhD}$; University of Calgary)

Heiba et al. [26] recently published a study using a protocol combining rest-redistribution with ${ }^{201} \mathrm{Tl}$ and lowdose dobutamine contractility assessment. Data for perfusion were obtained first by a single rest injection of ${ }^{201} \mathrm{Tl}$ with gated SPECT image acquisition. Then 4-hour delayed gated SPECT images were acquired during dobutamine infusion. Segments were analyzed for rest-redistribution ${ }^{201} \mathrm{Tl}$ perfusion (normal, reversible, and fixed decreased perfusion) and wall motion and/or wall-thickening difference (normal, fixed dysfunctional, improved dysfunctional contractility) with low-dose dobutamine. Furthermore, segments with a fixed decrease in ${ }^{201} \mathrm{Tl}$ uptake were subclassified into mild, moderate, and severe fixed segments. In this study, over half of the dysfunctional segments with either a mild to moderate fixed decrease in thallium uptake showed evidence of improved wall motion or wall thickening. Only $30 \%$ of the segments with a severe fixed defect on redistribution showed improvement. Using this protocol the authors could obtain complementary data regarding myocardial viability. Using not only perfusion-redistribution data, contractile reserve and regional contractility could simultaneously be assessed adding to the functional characterization of viable myocardium.
Perceived nonviable myocardium on ${ }^{201} \mathrm{Tl}$ imaging may actually have viable tissue identified with low-dose dobutamine potentially improving the prediction of patient outcomes and impacting management decisions. Another attractive feature is the routine ease of administration of lowdose dobutamine in the clinical setting. There is no additional ${ }^{201} \mathrm{Tl}$ injection or extra imaging time, making this protocol particularly attractive.

Thallium imaging remains the most utilized method for assessing myocardial viability. Important strides in research have been made to improve its specificity as highlighted above. However, other radionuclide modalities as well have also made important advances in the assessment of myocardial viability.

\section{Technetium-99-based SPECT}

${ }^{99 \mathrm{~m}} \mathrm{Tc}$-based radiopharmaceuticals currently available and used in daily clinical practice include sestamibi and tetrofosmin. To briefly review, they are lipid-soluble compounds that cross membranes through passive diffusion driven by the transmembrane electrochemical gradient ultimately being retained within the mitochondria of the myocyte [7]. In comparison to ${ }^{201} \mathrm{Tl},{ }^{99 \mathrm{~m}} \mathrm{Tc}$-based radiopharmaceuticals have a higher energy spectrum (140 vs $80 \mathrm{keV}$ ) and shorter half-life (enabling a higher dose) which can serve to improve image quality; but have a worse relationship to flow and minimal redistributing properties. However, mitochondrial uptake of these compounds requires an intact mitochondrial membrane and oxidative metabolism, thus the basis for sensitive viability detection [27-29]. A complete review of the properties and pharmacokinetics of ${ }^{99 \mathrm{~m}} \mathrm{Tc}$-based radiopharmaceuticals is available in any major textbook [30].

In prior studies, extent of myocardial scar has been consistently overestimated using ${ }^{99 \mathrm{~m}} \mathrm{Tc}$ compared to ${ }^{201} \mathrm{Tl}$ [31-33]. A recent study by Crean et al. [33] comparing ${ }^{18} \mathrm{~F}$ FDG, cardiac magnetic resonance imaging (CMR), and ${ }^{99 \mathrm{~m}}$ Tc-sestamibi (MIBI) found that a significantly higher number of segments were identified as scar by MIBI than by either ${ }^{18} \mathrm{~F}$-FDG or CMR. The greatest discrepancy between MIBI and ${ }^{18} \mathrm{~F}-\mathrm{FDG}$ and MRI was in detection of scar of the inferior and lateral wall. By the same token, nitrate (sublingual or intravenous) administration prior to MIBI imaging has been proposed to increase ability to detect myocardial viability while performing perfusion imaging. The exact mechanism is not well understood; however, it is theorized that nitrates improve myocardial blood flow to hypoperfused myocardial segments by dilating stenotic epicardial arteries. This may enable increased blood flow through collateral vessels to ischemic segments [34].

However, more important is the clinical decisions to be made from data provided by nitrate-augmented ${ }^{99 \mathrm{~m}} \mathrm{Tc}$ imaging. Yang et al. [34] recently reviewed data from eight 
${ }^{99 \mathrm{~m}} \mathrm{Tc}$-based studies utilizing nitrate imaging for viability detection (Table 1) [34-42]. There was a consistent agreement between the occurrence of cardiac events and nitrateaugmented myocardial perfusion imaging. Furthermore, Sorrentino et al. [41] compared patient prognosis and outcome between nitrate ${ }^{99 \mathrm{~m}} \mathrm{Tc}$-tetrofosmin SPECT and ${ }^{18} \mathrm{~F}$ FDG-PET. This study evaluated 89 patients with LV dysfunction due to CAD with both nitrate-assisted ${ }^{99 \mathrm{~m}} \mathrm{Tc}$ tetrofosmin SPECT and ${ }^{18}$ F-FDG-PET imaging. There was no significant difference in reported event-free survival in the viable myocardium group (and nonviable myocardium group) imaged with either SPECT or PET. The authors concluded that nitrate-assisted SPECT provided similar prognostic information to PET, thus not affecting patient management or outcome.

Administration of nitrates is easy, affordable, and effective in SPECT-assisted imaging for myocardial viability. Although scar-based quantitative and qualitative assessment may differ, patient outcomes and management decisions may not significantly be altered.

\section{PET Imaging}

\section{Fluorine-18-Fluorodeoxy-Glucose PET}

Cardiac PET utilizing ${ }^{18} \mathrm{~F}-\mathrm{FDG}$ is considered the most sensitive modality for detecting hibernating viable myocardium. The premise behind ${ }^{18} \mathrm{~F}-\mathrm{FDG}$ viability imaging relies on basic cardiac physiology during ischemia/injury. Under aerobic conditions and the fasting state, the preferential energy substrate of the heart is fatty acids. However, under conditions of ischemia or injury when oxidative metabolism is compromised, free fatty acid utilization is impaired, while glucose utilization is increased. Increased cardiac glucose utilization is also seen following an oral carbohydrate load. ${ }^{18} \mathrm{~F}-\mathrm{FDG}$ is a glucose analog, which is transported into cells though glucose membrane transporters GLUT1 and GLUT4, and subsequently phosphorylated by hexokinase to ${ }^{18}$ F-FDG-6-phosphate. FDG does not undergo any further metabolism (unlike glucose) and essentially is trapped within the cell as ${ }^{18} \mathrm{~F}$-FDG-6-phosphate. Trapped ${ }^{18} \mathrm{~F}$-FDG accumulates and becomes an index of cellular glucose utilization and hence ongoing cellular metabolism [43].

There are two key patterns of clinical significance identifying either scar or hibernating, viable myocardium. A match pattern is an equivalent reduction in perfusion and FDG uptake (reduced or absent glucose metabolism), thus signifying myocardial scar. Conversely, a mismatch pattern is a visible reduction in perfusion with preserved uptake of FDG, signifying glucose metabolism and thus viability. There is another pattern of preserved perfusion, yet reduced glucose metabolism on PET viability imaging described as "reverse mismatch" and likely represents viable myocardium. This pattern may be seen in left bundle branch block, nonischemic cardiomyopathy, or diabetes; and may be relevant in patients being considered for resynchronization therapy [44, 45].

Currently, ${ }^{18} \mathrm{~F}-\mathrm{FDG}$ PET is considered the most sensitive means of assessing viable myocardium and hence predicting LV functional recovery post-coronary revascularization $[2 \bullet \bullet, 4,5,46 \bullet \bullet, 47-54]$. Prior observational outcome studies have suggested that ${ }^{18}$ F-FDG PET can help

Table 1 Outcome data of eight reviewed ${ }^{99 \mathrm{~m}}$ Tc-based SPECT studies for viability

\begin{tabular}{|c|c|c|c|c|}
\hline \multirow[t]{2}{*}{ Author } & \multirow{2}{*}{$\begin{array}{l}\text { Follow-up } \\
\text { (mean, months) }\end{array}$} & \multirow[t]{2}{*}{ Cardiac events } & \multicolumn{2}{|l|}{ Viability and outcome } \\
\hline & & & Predictor & $\begin{array}{l}\text { Risk ratio } \\
(95 \% \mathrm{CI})\end{array}$ \\
\hline Basu et al. & 21 & $\begin{array}{l}\text { Cardiac death, nonfatal MI, unstable } \\
\text { angina, CHF }\end{array}$ & Reversible perfusion defects & $8.1(2.7-23.8)$ \\
\hline Sciagra et al. & 27 & Cardiac death, nonfatal MI & $\begin{array}{l}\text { Number of viable non-revascularized } \\
\text { asynergic segments }\end{array}$ & $1.4(1.19-1.65)$ \\
\hline Senior et al. & 40 & Cardiac death & Revascularization and $>4$ viable segments & $0.21(0.04-1.1)$ \\
\hline Kostkiewicz et al. & 25 & $\begin{array}{l}\text { Cardiac death, nonfatal MI, repeat } \\
\text { revascularization }\end{array}$ & $\begin{array}{l}\text { Number of viable non-revascularized } \\
\text { segments }\end{array}$ & $1.32(1.10-1.50)$ \\
\hline He et al. & 23 & Cardiac death, nonfatal MI & Number of viable segments & $1.24(1.04-1.47)$ \\
\hline Bosevski et al. & 12 & Cardiac death & Viability index & NI \\
\hline Acampa et al. & 43 & $\begin{array}{l}\text { Cardiac death, nonfatal MI, late } \\
\text { revascularization }\end{array}$ & Extent of viability & $1.6(1.3-2.0)$ \\
\hline Sorrentino et al. & 29 & $\begin{array}{l}\text { Cardiac death, nonfatal MI, late } \\
\text { revascularization }\end{array}$ & NI & NI \\
\hline Evangelista et al. & 30 & $\begin{array}{l}\text { Cardiac death, nonfatal MI, late } \\
\text { revascularization }\end{array}$ & NI & NI \\
\hline
\end{tabular}

$C H F$ chronic heart failure; $C I$ confidence interval; $M I$ myocardial infarction; NI, not included.

(Adapted from Yang et al. [34]; with permission from Wolters Kluwer Health.) 
identify patients at high risk for cardiac events [55]. The PET and Recovery Following Revascularization (PARR 2) randomized controlled trial of 430 patients investigated patients with an $\mathrm{EF}<35 \%$ and suspected or confirmed $\mathrm{CAD}$, who were considered for revascularization, transplant, or heart failure work-up. A standardized clinical report was produced by the interpreting physician detailing the amount of scar, viable myocardium, and degree of mismatch. The results along with the perceived likelihood of recovery were conveyed to the treating physician and a decision was made on an individual basis. PET-assisted decision-making compared to standard care showed a trend but did not reach statistical significance with respect to the primary composite end point (cardiac death, myocardial infarction, or recurrent hospital admission for cardiac causes). However, a post hoc analysis of the data was performed investigating adherence to PET recommendations. When management adhered to the imaging recommendations, a significant reduction in adverse outcomes was observed in the PET arm [3].

In a recent substudy of the PARR-2 trial, D'Egidio et al. $[2 \bullet \bullet]$ set out to determine the predictors of outcome. A total of 182 patients randomized to the PET arm of the PARR-2 trial were included. A key finding was the interaction of mismatch and revascularization such that as mismatch extent increased so too did the benefit of revascularization (Figs. 2, 3 and 4). In those patients with a mismatch score of $<7 \%$, there was no significant difference in the primary outcome regardless of whether revascularization was performed or not. However, patients with a mismatch score of $\geq 7 \%$ undergoing revascularization showed a decreased occurrence of the primary outcome. In addition, this study also identified plasma creatinine levels as an independent predictor of outcome, with baseline LV EF demonstrating a trend toward increased risk regardless of whether the patient had revascularization. Despite the post hoc nature of the analysis, this information may be helpful in identifying patients who will likely benefit from revascularization versus medical therapy and identify when the risk of revascularization is not justified.

Interestingly, Inaba et al. [56••], in a recent meta-analysis including seven ${ }^{18} \mathrm{~F}$-FDG PET studies, found the optimal cutoff value for the amount of viable myocardium to be $25.8 \%(\mathrm{CI}=16.6-35.0)$ that would lead to a survival benefit with revascularization in comparison to standard medical therapy. This was the lowest of any viability imaging method (Table 2). However, all of the data used in this meta-analysis represented observational data in which the

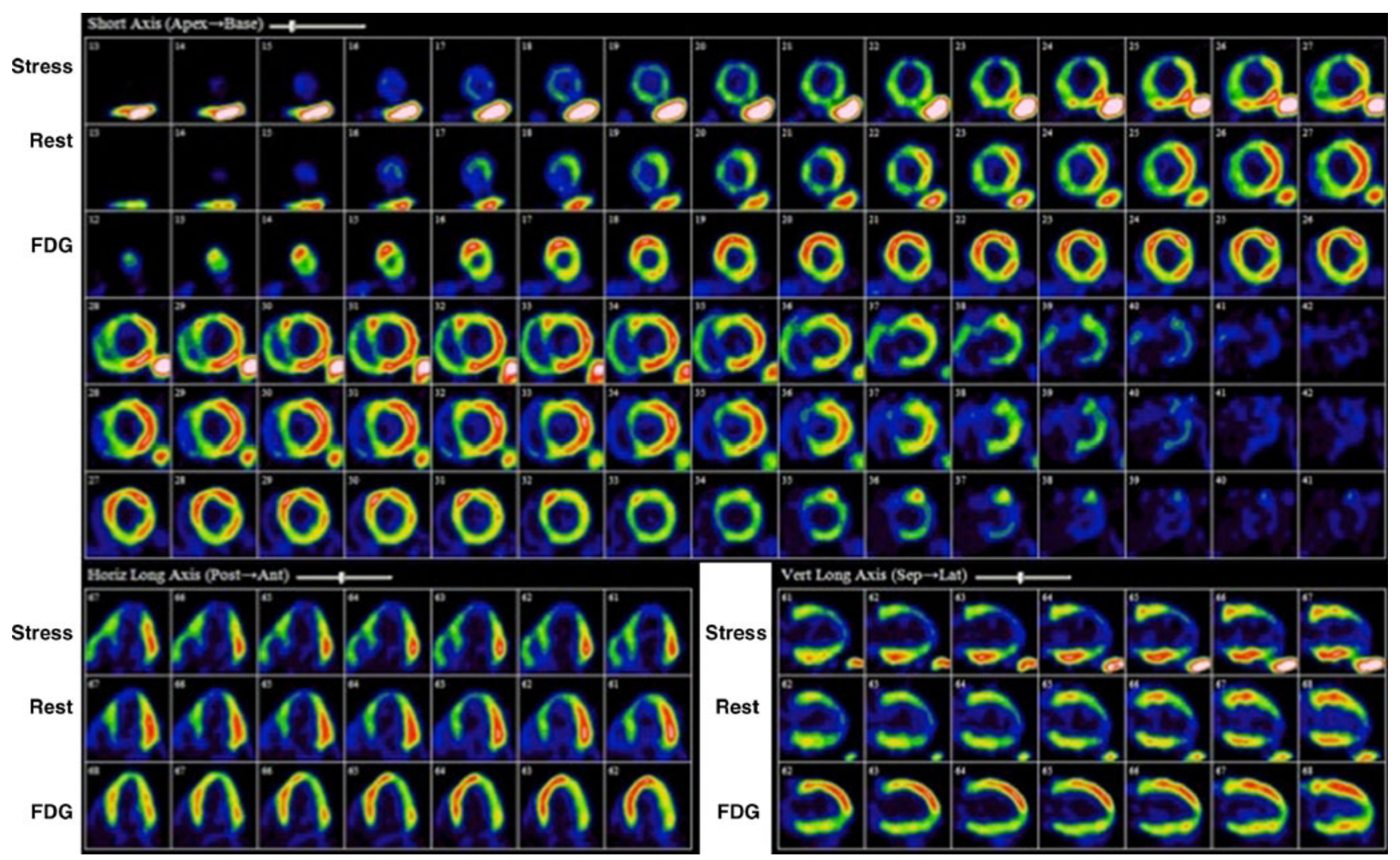

Fig. $2{ }^{82} \mathrm{Rb}$ stress and ${ }^{18} \mathrm{~F}$-FDG PET viability imaging. Top row, Stress images demonstrate a moderate to severe reduction in uptake in the anterior wall, apex, distal inferior wall, and septum with minimal improvement on rest (middle row), consistent with mild ischemia, transmural, and nontransmural scar in the LAD territory. Third row, ${ }^{18}$ F-FDG images demonstrate a mismatch pattern in the mentioned territories, signifying viable myocardium 


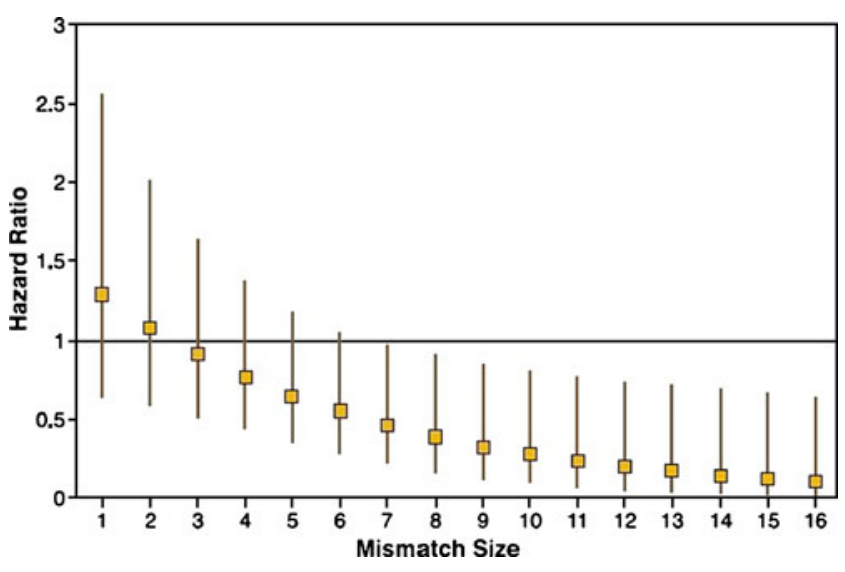

Fig. 3 Interaction hazard ratios and 95\% confidence interval at various levels of mismatch measured as a continuous variable. Patients with a mismatch score of $<7 \%$ showed no significant difference in the risk of the primary outcome if revascularization was performed or not. However, as the amount of mismatch increased ( $\geq 7 \%)$ there is a decrease in occurrence of the primary outcome for those who undergo revascularization. (Reprinted from D'Egidio et al. [2••]; with permission from Elsevier)

patient and physician contributed to the decision to treat, which may have contributed to the findings. As well the recent data from D'Egidio et al. were not considered.

Cardiac PET is not yet as widely available as SPECT imaging. Also, experience in interpretation and operation may vary widely. Established institutions routinely performing PET viability imaging may have higher accuracy, standardization protocols and reporting, and confidence of interpretation rates than centers with newly or part-time instituted PET programs, thus ultimately influencing management decisions. The Ottawa-FIVE substudy of the PARR-2 trial investigated the outcomes of a site with ready

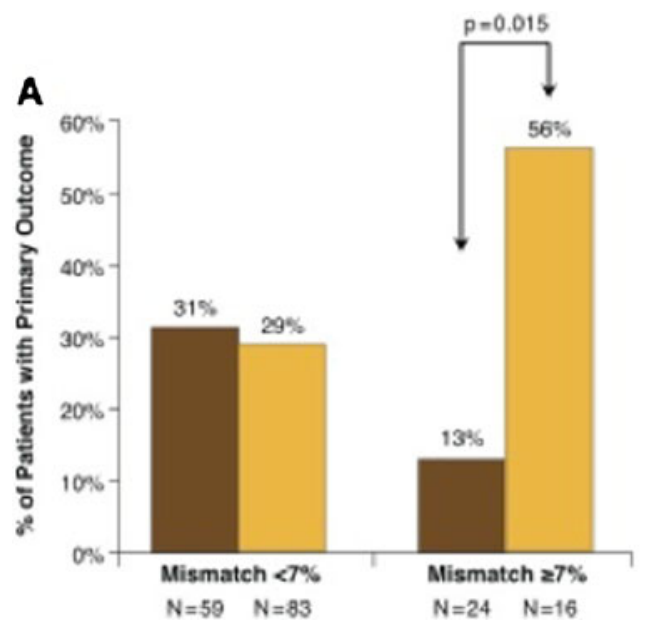

Fig. 4 The effect of revascularization or medical therapy on outcome (a) and cardiac death (b) in patients stratified according to amount of mismatch $(<7 \%$ or $\geq 7 \%)$. Note that in patients (a) with mismatch $<$ $7 \%$, there is no statistically significant difference in primary outcome whether revascularization is performed or not. However, in patients accessibility to ${ }^{18}$ F-FDG supply in addition to a comprehensive and integrative clinical management approach in patients with LV dysfunction and suspected CAD [57]. Patients enrolled in the PARR-2 trial in Ottawa, Canada were randomized into two groups: ${ }^{18} \mathrm{~F}-\mathrm{FDG}$ PET assisted management group and a standard care group. Patients with unsuitable anatomy for revascularization were excluded from the analysis. The primary event of interest was the composite of cardiac death, myocardial infarction, or cardiac hospitalization as in the main PARR 2 trial. In the ${ }^{18} \mathrm{~F}-\mathrm{FDG}$ PET group, 10 patients of $56(19 \%)$ experienced the primary end point compared to 22 of 55 patients $(41 \%)$ in the standard care group. Adjusted survival curves are shown in Fig. 5. However, when patients in the rest of the PARR-2 (non-Ottawa sites) were analyzed, there was no significant difference in occurrence of the composite end point between the PET arm and standard treatment arm. The findings of this substudy strongly suggest that clinical outcomes may be significantly improved in centers with ready access to ${ }^{18} \mathrm{~F}$-FDG PET imaging and experience with the methodology, in addition to an integrative approach incorporating heart failure, imaging, and revascularization teams. In Ottawa, cardiac PET has been an established method of perfusion and viability imaging with a dedicated PET scanner and internationally renowned PET research department. However, in the PARR-2 trial there were eight other recruiting sites, five of which did not have ready access to ${ }^{18} \mathrm{~F}$-FDG PET and three of which had more limited experience in terms of prior volume. As such, these sites and their respective clinical teams may have been less accustomed to interpreting and translating PET data into practice, potentially contributing to the nonsignificant trend toward benefit of the main PARR-2 study [57]. In light of these data, quality assurance programs have been established in regions,

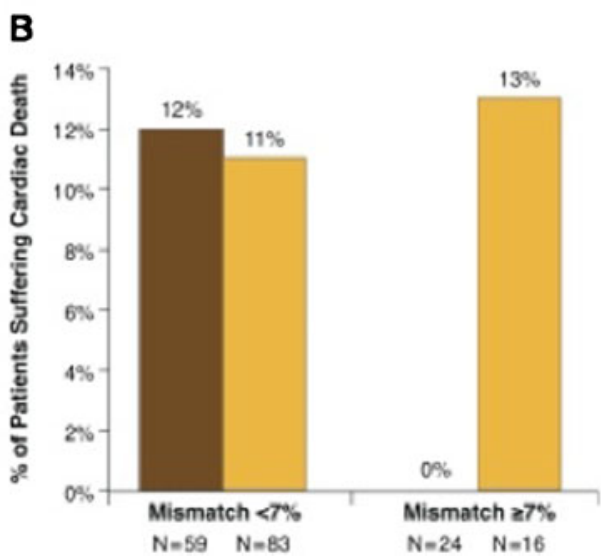

with $\geq 7 \%$ mismatch undergoing revascularization, the primary event significantly occurred less frequently than in patients not undergoing revascularization. Panel b shows similar results with respect to cardiac death. (Reprinted from D'Egidio et al. [2••]; with permission from Elsevier) 
Table 2 Optimal cutoff values for the presence of viability leading to improved survival with revascularization over medical therapy

\begin{tabular}{lcr}
\hline Imaging techniques (number of studies) & Mean viable myocardium (SD), $\%$ & Optimal threshold for viability, $\%$ \\
\hline PET overall $(n=7)$ & $21(13)$ & $25.8(16.6-35.0)$ \\
PET with FDG/ $/ \mathrm{NH}_{3}(n=3)$ & $20(15)$ & $22.5(10.1-34.8)$ \\
PET with FDG/ ${ }^{99 \mathrm{~m}} \mathrm{Tc}(n=3)$ & $22(16)$ & $29.2(20.7-37.8)$ \\
Stress echo overall $(n=8)$ & $32(24)$ & $35.9(31.6-40.3)$ \\
Stress echo with LDDE $(n=4)$ & $33(28)$ & $33.6(27.4-39.8)$ \\
Stress echo with HDDE $(n=2)$ & $35(31)$ & $44.1(37.2-50.9)$ \\
SPECT overall $(n=6)$ & $38(25)$ & $38.7(27.7-49.7)$ \\
SPECT with ${ }^{201} \mathrm{~T} 1(n=5)$ & $41(35)$ & $38.0(26.2-49.7)$ \\
\hline
\end{tabular}

$H D D E$ high-dose dobutamine echo; $L D D E$ low-dose dobutamine echo.

(From Inaba et al. [56••]; with permission from Springer.)

such as the Cardiac FDG PET Registry (CADRE) in Ontario, Canada, whereby sites are trained and clinical scans are regularly reviewed to provide technical and clinical feedback to sites that are establishing new FDG PET imaging programs [58, 59].

With more data and ongoing investigation, ${ }^{18}$ F-FDG PET imaging will likely continue to be a key modality into the investigation of myocardial viability. Image quality and confidence in interpretation is high with PET imaging, and this can be attributed to many factors, such as camera technology, attenuation correction techniques, and the pathophysiology of hibernation and its effect on FDG/ glucose metabolism among others. However, a very important question is how PET data, imaging, and interpretation can impact clinical outcomes in comparison to SPECT imaging. Outcome comparison studies are limited to date but a multicenter randomized trial is now underway (IMAGE-HF), which will evaluate and compare heart failure patients using ${ }^{18}$ F-FDG PET, SPECT, and CMR, and how relevant clinical decisions and outcomes are impacted [60] by the different approaches.

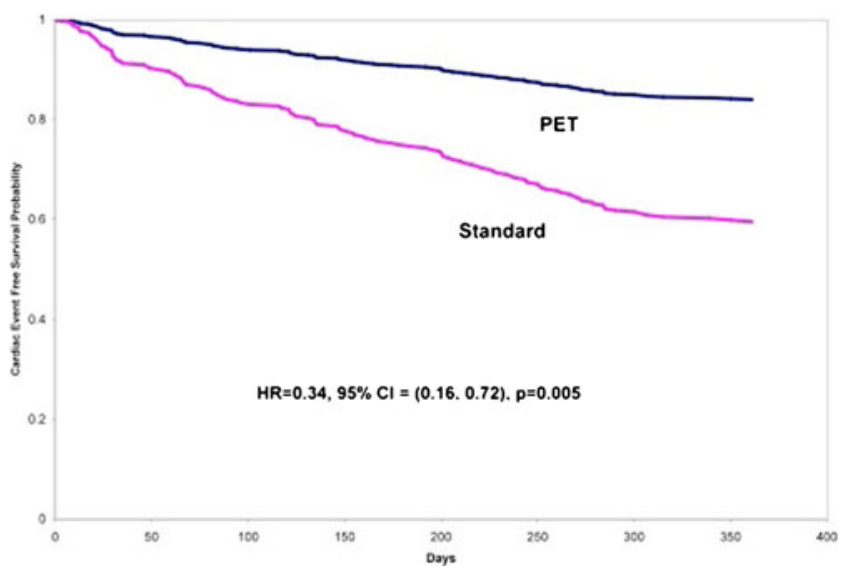

Fig. 5 Adjusted survival curves for PET and standard care arms in the Ottawa-Five Substudy. (Reprinted from Abraham et al. [57]; with permission from the Society of Nuclear Medicine)

\section{Comparison to Other Viability Modalities}

Other modalities commonly used to assess myocardial viability include low-dose dobutamine stress echocardiography (LD-DSE) and cardiac MRI. The basic premise behind LD-DSE is that it induces contractility as an expression of the contractile reserve of dysfunctional yet viable myocardium, displaying a biphasic response. At low-dose dobutamine $(5 \mathrm{mg} / \mathrm{kg})$, there is recruitment of contractile reserve with improvement in wall motion and thickening. However, at higher doses of dobutamine, wall motion becomes impaired due to stress-induced subendocardial ischemia [61]. If, however, a territory is nonviable and consists mostly of scar, there will be relatively little to no improvement in wall motion with dobutamine. In a meta-analysis that included 1421 patients from 41 studies who underwent LD-DSE, and also compared ${ }^{201} \mathrm{Tl}$ SPECT, ${ }^{18} \mathrm{~F}$-FDG PET, ${ }^{99 \mathrm{~m}} \mathrm{Tc}$-based SPECT, and CMR, specificity was highest for LD-DSE but LD-DSE had reduced sensitivity compared to radionuclide methods [46••]. Observational outcome studies and a systematic review that included 1645 patients from 10 studies have demonstrated that LD-DSE also identified patients with viable myocardium who had a high risk for cardiac events if they did not undergo revascularization, although the increment of this risk did not appear to be as great as it was with ${ }^{18}$ F-FDG PET [46••]. In the work by Inaba et al. [56••], $35.9 \%(\mathrm{CI}=31.6-40.3)$ of the LV had to be viable using LDDSE to predict a survival benefit with revascularization in comparison to standard medical therapy (Table 2).

There are two common methods to assess viability via CMR: dobutamine stress CMR, which uses the same principles as dobutamine echocardiography, and delayed enhancement CMR (DE-CMR), which takes advantage of the kinetic properties of contrast to identify regions of scar. Pooled data report the sensitivity and specificity of dobutamine stress CMR in the detection of viable myocardium to be $91 \%$ and $94 \%$, respectively, and DE-CMR a sensitivity of $81 \%$ and specificity of $83 \%$ [55]. DE-CMR has been used to 
predict functional LV recovery after acute myocardial infarction [62], predict functional LV response to myocardial revascularization in patients with chronic ischemic heart disease [63, 64], and predict response to medical therapy in patients with LV dysfunction [65]. In a comparison of ${ }^{18} \mathrm{~F}$ FDG SPECT, ${ }^{99 \mathrm{~m}} \mathrm{Tc}-\mathrm{SPECT}$, and DE-CMR, there was a close correlation between ${ }^{18} \mathrm{~F}-\mathrm{FDG}$ and DE-CMR techniques, although ${ }^{99 \mathrm{~m}} \mathrm{Tc}$ - SPECT overestimated the amount of scar [33]. In another similar study investigating myocardial viability in 60 patients with severe ischemic LV dysfunction, correlation was good between ${ }^{18} \mathrm{~F}$-FDG SPECT and DE-CMR; however, this was limited to segments with either transmural scar or no scar tissue at all [66]. In segments with nontransmural or subendocardial scar agreement was lacking. In a meta-analysis that included 421 patients from 13 studies who underwent cMRI, and compared ${ }^{201} \mathrm{Tl}$ SPECT, ${ }^{18} \mathrm{~F}$-FDG PET, ${ }^{99 \mathrm{~m}}$ Tc-based SPECT, and LD-DSE, prediction of functional recovery after revascularization appeared comparable to Tc-99 m-based SPECT but was not as sensitive as ${ }^{18} \mathrm{~F}$-FDG PET nor as specific as LD-DSE [46••]. While outcome studies have been done with CMR, they are limited in number and do not focus on patients with the most severe LV dysfunction where viability is most relevant. In the study by Inaba et al. [56••] $25.8(\mathrm{CI}=$ 16.6-35.5) of the LV had to be viable using PET to predict a survival benefit with revascularization in comparison to standard medical therapy (Table 2).

Although each modality attempts to assess myocardial viability in a different manner (ie, radiotracer uptake reflecting cell integrity, contractile reserve, delayed gadolinium enhancement), these modalities strive to provide the same basic information: is the tissue viable or not? They should not be viewed as competing modalities. Instead, these modalities should be viewed as complementary methods evaluating different aspects of the same problem. A clinician now has a wide variety of modalities to choose from, selecting the most appropriate for the patient and taking into account desire for sensitivity or specificity, comorbidities, indications, contraindications, availability, and local expertise [67]. Studies such as IMAGE HF will help to ascertain which methods are most suitable for which types of patient [60].

\section{Why Viability?}

Current American College of Cardiology (ACC) published guidelines on heart failure (ACC-focused update 2009 of 2005 guidelines) assign a IIa recommendation to viability assessment in patients with heart failure, known CAD, and the absence of angina. Additionally, they suggest that further studies are needed to determine the usefulness of routine myocardial viability assessment in patients with ischemic-LV dysfunction in the absence of angina [68].
However, the Canadian Cardiovascular Society (CCS guidelines 2006) states as a class I indication that patients with large areas of viability should be evaluated for revascularization [69]. The joint appropriateness criteria published by the ACCF/ASNC/ACR/ASE/SCCT/SCMR/ SNM in 2009 assign an appropriate use score of 9 (highest indication) for assessment of myocardial viability in ischemic cardiomyopathy patients with reduced LV function [70]. The $\mathrm{CCS} / \mathrm{CAR} / \mathrm{CANM} / \mathrm{CNCS} / \mathrm{CanSCMR}$ joint position statement on advanced noninvasive imaging strongly supports (class I recommendation) the use of cardiac PET and CMR in the evaluation and prognostication of patients with ischemic cardiomyopathy and LV dysfunction [55].

Radionuclide myocardial viability imaging has continually grown together with the concept of hibernation and stunning. As we learn more about the pathophysiologic mechanisms behind myocardial viability, research is being directed into understanding the clinical ramifications of the data, interpretations, and clinical recommendations that these modalities provide. As discussed above, there is credible evidence that in patients with moderate to severe LV dysfunction, myocardial viability is best treated with revascularization for survival benefit. Also, given recent studies $[2 \bullet \bullet, 56 \bullet \bullet$, we are learning more about the optimal amount of viable myocardium in order to yield a positive outcome benefit. However, many more issues remain unanswered that impact patient outcomes. Issues such as quality of life, arrhythmic benefit, CCS and NYHA class of symptoms, and health care costs are also important but remain under-investigated. Many physicians may avoid radionuclide viability imaging based on preconceptions that either no benefit can be obtained in LV dysfunction, or that benefit is achieved with revascularization regardless of the presence of viability. However, as previously shown, there is a considerable increase in risk of stroke and death in patients with severe LV dysfunction undergoing revascularization (post-coronary artery bypass surgery outcome in 30 days: stroke $\sim 3 \%$, death $\sim 5 \%$ ) [1].

\section{Conclusions}

The decision to proceed with revascularization should be a carefully educated clinical decision that takes into account evidence, advantages, disadvantages, and risk. Radionuclide imaging can help detect, quantify, and risk stratify patients who will likely benefit from revascularization. In other patients, radionuclide imaging can help prevent unnecessary intervention risk that can lead to poor clinical outcomes.

Although methods such as CMR have become popular despite the lack of outcome studies, the strength of the data and the large number of prior outcome studies suggest that radionuclide methods should be used more widely when there is a question regarding viability. Given the benefits of 
radionuclide imaging methods for myocardial viability (in particular their sensitivity), the range of modality options, and their widespread availability, they should be applied more routinely in patients with ischemic cardiomyopathy where revascularization is an option.

Acknowledgments Dr. Beanlands is a Career Investigator supported by the Heart and Stroke Foundation of Ontario (HSFO). Dr. Mylonas is a Clinical/Research Fellow supported by the Vered-Beanlands Cardiology Endowed Research Fellowship, the Division of Cardiology, University of Ottawa Heart Institute, and the Molecular Function and Imaging (MFI) Program (HSFO program grant \# PRG6242). The project was supported in part by the MFI HSFO program grant and IMAGE Heart Failure Team (Canadian Institutes for Health Research).

Disclosure I. Mylonas: none; R.S.B. Beanlands: consultant for DraxImage and Lantheus Medical Imaging and has received grant funding from a government/industry program (partners: GE Healthcare and MDSNordion).

Open Access This article is distributed under the terms of the Creative Commons Attribution Noncommercial License which permits any noncommercial use, distribution, and reproduction in any medium, provided the original author(s) and source are credited.

\section{References}

Papers of particular interest, published recently, have been highlighted as:

-• Of major importance

1. Jones RH, Velazquez EJ, Michler RE, Sopko G, Oh JK, O'Connor $\mathrm{CM}$, et al. Coronary bypass surgery with or without surgical ventricular reconstruction. N Engl J Med. 2009;360(17):1705-17.

2. •• D'Egidio G, Nichol G, Williams K, Guo A, Garrard L, deKemp R, Ruddy T, DaSilva J, Humen D, Gulenchyn K, Freeman M, Racine N, Benard F, Hendry P, Beanlands R. Identification of High-Risk Patients With Increasing Ischemic Cardiomyopathy. JACC Cardiovasc Imaging 2009;2(9):1060-68. This substudy identifies the amount of mismatch ("mismatch score") needed to derive benefit from revascularization in patients from the PET arm of the PARR-2 Study.

3. Beanlands R, Nichol G, Huszti E, Humen D, Racine N, Freeman $\mathrm{M}$, et al. Investigators $\mathrm{P}$. F-18-Fluorodeoxyglucose Positron Emission Tomography Imaging-Assisted Management of Patients with Severe Left Ventricular Dysfunction and Suspected Coronary Disease. A Randomized Controlled Trial (PARR-2). J Am Coll Cardiol. 2007;50(20):2002-12.

4. Zhang X, Liu XJ, Wu Q, Shi R, Gao R, Liu Y, et al. Clinical outcome of patients with previous myocardial infarction and left ventricular dysfunction assessed with myocardial (99m)Tc-MIBI SPECT and (18)F-FDG PET. J Nucl Med. 2001;42(8):1166-73.

5. Allman KC, Shaw LJ, Hachamovitch R, Udelson JE. Myocardial viability testing and impact of revascularization on prognosis in patients with coronary artery disease and left ventricular dysfunction: a meta-analysis. J Am Coll Cardiol. 2002;39(7):1151-8.

6. Schinkel AF, Poldermans D, Rizzello V, Vanoverschelde JL, Elhendy A, Boersma E, et al. Incidence of recovery of contractile function following revascularization in patients with ischemic left ventricular dysfunction. Am J Cardiol. 2004;93(1):14-7.
7. Libby P, Bonow R, Zipes D, Mann D. Braunwald's heart disease: A textbook of cardiovascular medicine. 8th Edn ed: Elsevier; 2007.

8. Stirrup J, Maenhout A, Wechalekar K, Anagnostopoulos C. Radionuclide imaging in ischaemic heart failure. Br Med Bull. 2009;92:43-59.

9. Camici PG, Wijns W, Borgers M, De Silva R, Ferrari R, Knuuti J, et al. Pathophysiological mechanisms of chronic reversible left ventricular dysfunction due to coronary artery disease (hibernating myocardium). Circulation. 1997;96(9):3205-14.

10. Pagano D, Fath-Ordoubadi F, Beatt KJ, Townend JN, Bonser RS, Camici PG. Effects of coronary revascularisation on myocardial blood flow and coronary vasodilator reserve in hibernating myocardium. Heart. 2001;85(2):208-12.

11. Vanoverschelde J-LJ, Wijns W, Depre C, Essamri B, Heyndrickx G, Borgers $\mathrm{M}$, et al. Mechanisms of chronic regional postischemic dysfunction in humans. New insights from the study of noninfarcted collateral-dependent myocardium. Circulation. 1993;87(5):1513-23.

12. Ghosh N, Rimoldi OE, Beanlands RS, Camici PG. Assessment of myocardial ischaemia and viability: role of positron emission tomography. Eur Heart $J$.

13. Carluccio E, Biagioli P, Alunni G, Murrone A, Giombolini C, Ragni $\mathrm{T}$, et al. Patients with hibernating myocardium show altered left ventricular volumes and shape, which revert after revascularization: evidence that dyssynergy might directly induce cardiac remodeling. J Am Coll Cardiol. 2006;47(5):969-77.

14. Strauss HW, Harrison K, Langan JK, Lebowitz E, Pitt B. Thallium-201 for myocardial imaging. Relation of thallium-201 to regional myocardial perfusion. Circulation. 1975;51(4):641-5.

15. Weich HF, Strauss HW, Pitt B. The extraction of thallium-201 by the myocardium. Circulation. 1977;56:188-91.

16. Grunwald AM, Watson DD, Holzgrefe Jr HH, Irving JF, Beller GA. Myocardial thallium-201 kinetics in normal and ischemic myocardium. Circulation. 1981;64(3):610-8.

17. Okada RD, Boucher CA. Differentiation of viable and nonviable myocardium after acute reperfusion using serial thallium-201 imaging. Am Heart J. 1987;113(2 Pt 1):241-50.

18. Kiat H, Berman DS, Maddahi J, De Yang L, Van Train K, Rozanski A, et al. Late reversibility of tomographic myocardial thallium-201 defects: an accurate marker of myocardial viability. J Am Coll Cardiol. 1988;12(6):1456-63.

19. He YM, Yang XJ, Wu YW, Zhang B. Twenty-four-hour thallium-201 imaging enhances the detection of myocardial ischemia and viability after myocardial infarction: a comparison study with echocardiography follow-up. Clin Nucl Med. 2009;34(2):65-9.

20. Gutman J, Berman DS, Freeman M, Rozanski A, Maddahi J, Waxman A, et al. Time to completed redistribution of thallium201 in exercise myocardial scintigraphy: relationship to the degree of coronary artery stenosis. Am Heart J. 1983;106(5 Pt 1):989-95.

21. Bonow RO, Dilsizian V, Cuocolo A, Bacharach SL. Identification of viable myocardium in patients with chronic coronary artery disease and left ventricular dysfunction: comparison of thallium scintigraphy with reinjection and PET imaging with $18 \mathrm{~F}$ fluorodeoxyglucose. Circulation. 1991;83:26-37.

22. Dilsizian V, Rocco TP, Freedman NMT, Leon MB, Bono RO. Enhanced detection of ischemic but viable myocardium by the reinjection of thallium after stress-redistribution imaging. N Engl $\mathbf{J}$ Med. 1990;323(3):141-6.

23. Toyama T, Hoshizaki H, Seki R, Isobe N, Oshima S, Taniguchi K, et al. Evaluation of myocardial viability following acute myocardial infarction using 201Tl SPECT after thallium-glucose-insulin infusion-comparison with $18 \mathrm{~F}-\mathrm{FDG}$ positron emission tomography. Ann Nucl Med. 2004;18(6):463-8.

24. Chiba H, Kusuoka H, Ohno J, Nishimura T. Glucose-loading thallium-201 myocardial SPECT. J Nucl Med. 1997;38(4):573-7. 
25. Hasbek Z, Turgut B, Erselcan T, Yalta K, Tandogan I, Ozer G, et al. Evaluation of myocardial viability with thallium-201 infusion MPSPECT after oral glucose application in patients with chronic coronary artery disease. Nucl Med Commun. 2009;30(10):77988.

26. Heiba SI, Yee G, Abdel-Dayem HM, Youssef I, Coppola J. Combined rest redistribution thallium-201 SPECT and low-dose dobutamine contractility assessment in a simple and practical new viability protocol. Ann Nucl Med. 2009;23(2):197-203.

27. Jain D. Technetium-99m labeled myocardial perfusion imaging agents. Semin Nucl Med. 1999;29(3):221-36.

28. Demirkol MO. Myocardial viability testing in patients with severe left ventricular dysfunction by SPECT and PET. Anadolu Kardiyol Derg. 2008;8 Suppl 2:60-70.

29. Beanlands R, Dawood F, Wen WH, McLaughlin PR, Butany J, D'Amati G, et al. Are the kinetics of Technetium 99m-methoxy isobutyl isonitrile affected by cell metabolism and viability? Circulation. 1990;82(5):1802-14.

30. Zaret B, Beller G. Clinical nuclear cardiology: State of the art and future directions. 4th ed. Philadelphia: Mosby Elsevier; 2010.

31. Cuocolo A, Pace L, Ricciardelli B, Chiariello M, Trimarco B, Salvatore M. Identification of viable myocardium in patients with chronic coronary artery disease: comparison of thallium-201 scintigraphy with reinjection and technetium-99m-methoxyisobutyl isonitrile. J Nucl Med. 1992;33(4):505-11.

32. Marzullo P, Sambuceti G, Parodi O. The role of sestamibi scintigraphy in the radioisotopic assessment of myocardial viability. J Nucl Med. 1992;33(11):1925-30.

33. Crean A, Khan SN, Davies LC, Coulden R, Dutka DP. Assessment of myocardial scar; Comparison between F-FDG PET, CMR and Tc-Sestamibi. Clin Med Cardiol. 2009;3:69-76.

34. Yang MF, Keng F, He ZX. Nitrate-augmented myocardial perfusion imaging for assessment of myocardial viability: recent advances. Nucl Med Commun. 2009;30(6):415-9.

35. Sciagra R, Pellegri M, Pupi A, Bolognese L, Bisi G, Carnovale V, et al. Prognostic implications of Tc-99m sestamibi viability imaging and subsequent therapeutic strategy in patients with chronic coronary artery disease and left ventricular dysfunction. J Am Coll Cardiol. 2000;36(3):739-45.

36. Senior R, Kaul S, Raval U, Lahiri A. Impact of revascularization and myocardial viability determined by nitrate-enhanced Tc- $99 \mathrm{~m}$ sestamibi and Tl-201 imaging on mortality and functional outcome in ischemic cardiomyopathy. J Nucl Cardiol. 2002;9 (5):454-62.

37. Kostkiewicz M, Olszowska M, Przewlocki T, Podolec P, Tracz W. Prognostic value of nitrate enhanced Tc99m MIBI SPECT study in detecting viable myocardium in patients with coronary artery disease. Int J Cardiovasc Imaging. 2003;19(2):129-35.

38. He ZX, Yang MF, Liu XJ, Shi RF, Gao RL, Hu SS, et al. Association of myocardial viability on nitrate-augmented technetium-99m hexakis-2-methoxylisobutyl isonitrile myocardial tomography and intermediate-term outcome in patients with prior myocardial infarction and left ventricular dysfunction. Am J Cardiol. 2003;92(6):696-9.

39. Bosevski M, Peovska I, Maksimovic J, Vavlukis M, Meskovska S. Prognostic utility of carotid ultrasound and cardiac SPECT imaging in coronary artery bypass patients. Nucl Med Rev Cent East Eur. 2006;9(1):12-7.

40. Acampa W, Evangelista L, Sorrentino AR, Petretta M, Luongo L, Cuocolo A. Single-photon emission computed tomography after nitrate administration predicts cardiac events in patients with previous myocardial infarction and left ventricular dysfunction. J Card Fail. 2007;13(9):765-8.

41. Sorrentino AR, Acampa W, Petretta M, Mainolfi C, Salvatore M, Cuocolo A. Comparison of the prognostic value of SPECT after nitrate administration and metabolic imaging by PET in patients with ischaemic left ventricular dysfunction. Eur J Nucl Med Mol Imaging. 2007;34(4):558-62.

42. Evangelista L, Acampa W, Petretta M, Ferro A, Ricci F, Luongo $\mathrm{L}$, et al. Incremental prognostic value of cardiac single-photon emission computed tomography after nitrate administration in patients with ischemic left ventricular dysfunction. J Nucl Cardiol. 2009;16(1):38-44.

43. Beanlands R, Thorn S, DaSilva J, Ruddy T, Maddahi J. Myocardial viability. In: Wahl R, editor. Principles and practices of positron emission tomography. 2nd ed. Philadelphia: Lippincott Williams and Wilkins; 2008.

44. Birnie D, DeKemp RA, Ruddy TD, Tang AS, Guo A, Williams K, et al. Effect of lateral wall scar on reverse remodeling with cardiac resynchronization therapy. Heart Rhythm. 2009;6(12):1721-6.

45. Inoue $\mathrm{N}$, Takahashi $\mathrm{N}$, Ishikawa $\mathrm{T}$, Sumita $\mathrm{S}$, Kobayashi $\mathrm{T}$, Matsushita K, et al. Reverse perfusion-metabolism mismatch predicts good prognosis in patients undergoing cardiac resynchronization therapy: a pilot study. Circ J. 2007;71(1):126-31.

46. • Schinkel AF, Bax JJ, Poldermans D, Elhendy A, Ferrari R, Rahimtoola SH. Hibernating myocardium: diagnosis and patient outcomes. Curr Probl Cardiol. 2007;32(7):375-410. This study compares the sensitivities and specificities of multiple imaging modalities for the prediction of recovery of regional function after revascularization. FDG PET was found to have the highest sensitivity, while dobutamine echocardiography was found to have the highest specificity.

47. Eitzman D, Al-Aouar Z, Kanter HL, vom Dahl J, Kirsch M, Deeb $\mathrm{GM}$, et al. Clinical outcome of patients with advanced coronary artery disease after viability studies with positron emission tomography. J Am Coll Cardiol. 1992;20(3):559-65.

48. Haas F, Haehnel C, Picker W, Nekolla S, Martinoff S, Meisner H, et al. Preoperative positron emission tomographic viability assessment and perioperative and postoperative risk in patients with advanced ischemic heart disease. J Am Coll Cardiol. 1997;30 (7):1693-700.

49. Yoshida K, Gould KL. Quantitative relation of myocardial infarct size and myocardial viability by positron emission tomography to left ventricular ejection fraction and 3-year mortality with and without revascularization. J Am Coll Cardiol. 1993;22:984-97.

50. VomDahl J, Altehoefer C, Sheehan FH, Buechin P, Schulz G, Schwarz ER, et al. Effect of myocardial viability assessed by technetium-99m-sestamibi SPECT and fluorine-18-FDG PET on clinical outcome in coronary artery disease. J Nucl Med. 1997;38 (5):742-8.

51. Desideri A, Cortigiani L, Christen AI, Coscarelli S, Gregori D, Zanco P, et al. The extent of perfusion-F18-fluorodeoxyglucose positron emission tomography mismatch determines mortality in medically treated patients with chronic ischemic left ventricular dysfunction. J Am Coll Cardiol. 2005;46(7):1264-9.

52. Di Carli M, Maddahi J, Rokhsar S, HR S, Bianco-Batlles D, RC $\mathrm{B}$, et al. Long-term survival of patients with coronary artery disease and left ventricular dysfunction: implications for the role of myocardial viability assessment in management decisions. J Thorac Cardiovasc Surg. 1998;116(6):997-1004.

53. Pagano D, Lewis M, Townend J, Davies P, Camici P, Bonser R. Coronary revascularization for postischaemic heart failure: how myocardial viability affects survival. Heart. 1999;82(6):684-8.

54. Di Carli MF, Davidson M, Little R, Khanna S, Mody FV, Brunken $\mathrm{RC}$, et al. Value of metabolic imaging with positron emission tomography for evaluating prognosis in patients with coronary artery disease and left ventricular dysfunction. Am J Cardiol. 1994;73(8):527-33.

55. Beanlands RS, Chow BJ, Dick A, Friedrich MG, Gulenchyn KY, Kiess M, et al. CCS/CAR/CANM/CNCS/CanSCMR joint position statement on advanced noninvasive cardiac imaging using positron 
emission tomography, magnetic resonance imaging and multidetector computed tomographic angiography in the diagnosis and evaluation of ischemic heart disease-executive summar. Can J Cardiol. 2007;23(2):107-19.

56. •• Inaba Y, Chen JA, Bergmann SR. Quantity of viable myocardium required to improve survival with revascularization in patients with ischemic cardiomyopathy: A meta-analysis. J Nucl Cardiol. 2010; Published online. This is a meta-analysis of SPECT, PET, and stress echo showing the amount of viable myocardium needed to produce a survival benefit in patients undergoing revascularization. PET required the least amount of viable myocardium of all other imaging modalities to produce a survival benefit.

57. Abraham A, Nichol G, Williams KA, Guo A, deKemp RA, Garrard L, et al. 18F-FDG PET imaging of myocardial viability in an experienced center with access to $18 \mathrm{~F}-\mathrm{FDG}$ and integration with clinical management teams: the Ottawa-FIVE substudy of the PARR 2 trial. J Nucl Med. 2010;51(4):567-74.

58. Renaud J, Klein R, DaSilva J, Beanlands R, DeKemp R. Comparison of $3 \mathrm{D}$ versus $2 \mathrm{D} 13 \mathrm{~N}$-ammonia PET myocardial perfusion imaging. J Nucl Med. 2010;51 Suppl 2:44P.

59. Ziadi MC, Beanlands R, DeKemp R, Renaud J, RE T, Guo A, et al. Impaired MFR measured using Rb-82 predicts outcomes in patients with suspected ischemia. Circulation. 2009;120: S320.

60. Paterson I, O'Meara E, Chow B, Ukkonen H, Beanlands R. Advances in Cardiac Imaging for Patients with Heart Failure. Curr Opin Cardiol. 2010;in press.

61. Cornel JH, Bax JJ, Elhendy A, Maat AP, Kimman GJ, Geleijnse $\mathrm{ML}$, et al. Biphasic response to dobutamine predicts improvement of global left ventricular function after surgical revascularization in patients with stable coronary artery disease: implications of time course of recovery on diagnostic accuracy. J Am Coll Cardiol. 1998;31(5):1002-10.

62. Choi KM, Kim RJ, Gubernikoff G, Vargas JD, Parker M, Judd RM. Transmural extent of acute myocardial infarction predicts long-term improvement in contractile function. Circulation. 2001;104 (10):1101-7.

63. Kim RJ, Wu E, Rafael A, Chen EL, Parker MA, Simonetti O, et al. The use of contrast-enhanced magnetic resonance imaging to identify reversible myocardial dysfunction. N Engl J Med. 2000;343 (20):1445-53.
64. Schvartzman PR, Srichai MB, Grimm RA, Obuchowski NA, Hammer DF, McCarthy PM, et al. Nonstress delayed-enhancement magnetic resonance imaging of the myocardium predicts improvement of function after revascularization for chronic ischemic heart disease with left ventricular dysfunction. Am Heart J. 2003;146 (3):535-41.

65. Bello D, Shah DJ, Farah GM, Di Luzio S, Parker M, Johnson MR, et al. Gadolinium cardiovascular magnetic resonance predicts reversible myocardial dysfunction and remodeling in patients with heart failure undergoing beta-blocker therapy. Circulation. 2003; 108(16):1945-53.

66. Roes SD, Kaandorp TA, Marsan NA, Westenberg JJ, DibbetsSchneider P, Stokkel MP, et al. Agreement and disagreement between contrast-enhanced magnetic resonance imaging and nuclear imaging for assessment of myocardial viability. Eur J Nucl Med Mol Imaging. 2009;36(4):594-601.

67. Chareonthaitawee P, Gersh BJ, Araoz PA, Gibbons RJ. Revascularization in severe left ventricular dysfunction: the role of viability testing. J Am Coll Cardiol. 2005;46(4):567-74.

68. Hunt SA, Abraham WT, Chin MH, Feldman AM, Francis GS, Ganiats TG, et al. 2009 focused update incorporated into the ACC/AHA 2005 Guidelines for the diagnosis and management of heart failure in adults: a report of the American College of Cardiology Foundation/American Heart Association Task Force on Practice Guidelines: developed in collaboration with the International Society for Heart and Lung Transplantation. Circulation. 2009;119(14):e391-479.

69. Arnold JM, Liu P, Demers C, Dorian P, Giannetti N, Haddad H, et al. Canadian cardiovascular society consensus conference recommendations on heart failure 2006: diagnosis and management. Can J Cardiol. 2006;22(1):23-45.

70. Hendel RC, Berman DS, Di Carli MF, Heidenreich PA, Henkin RE, Pellikka PA, et al. ACCF/ASNC/ACR/AHA/ASE/SCCT/ SCMR/SNM 2009 appropriate use criteria for cardiac radionuclide imaging: a report of the American college of cardiology foundation appropriate use criteria task force, the American society of nuclear cardiology, the American college of radiology, the American heart association, the American society of echocardiography, the society of cardiovascular computed tomography, the society for cardiovascular magnetic resonance, and the society of nuclear medicine. J Am Coll Cardiol. 2009;53 (23):2201-29. 